\title{
Oxidant/antioxidant imbalance in smokers and chronic obstructive pulmonary disease
}

An imbalance between oxidants and antioxidants has been proposed in the pathogenesis of chronic obstructive pulmonary disease (COPD). ${ }^{1}$ Although much research has focused on the protease/antiprotease theory of the pathogenesis of COPD, particularly emphysema, less attention has been paid to the role of the oxidant/antioxidant imbalance in this condition. This is surprising since cigarette smoke, which is the major risk factor for the development of COPD, contains $10^{17}$ oxidant molecules per puff of which $10^{14}$ are oxygen free radicals. ${ }^{2}$ There is a delicate balance between the toxicity of oxidants and the protective function of the intracellular and extracellular antioxidant defence systems which is critically important for the maintenance of normal pulmonary cellular functions. ${ }^{3}$ In this editorial we will examine the oxidant/antioxidant imbalance in smokers and patients with COPD to determine if there is enough evidence to warrant therapeutic trials with antioxidant therapy in patients with COPD.

Cigarette smoke is a complex mixture of over 4700 chemical compounds including high concentrations of oxidants and free radicals present in both the gas phase and the tar phase of cigarette smoke. ${ }^{24}$ Those in the gas phase are both organic and inorganic including reactive oxygen species and free radicals, aldehydes, peroxides and oxides of nitrogen. In the tar phase radicals are stable and predominantly organic, such as semiquinone which can react to produce superoxide anion $\left(\mathrm{O}_{2}^{-}\right)$.

Short lived radicals in the gas phase of cigarette smoke may be quenched immediately in the epithelial lining fluid (ELF); however, redox reactions in cigarette smoke condensate may produce reactive oxygen intermediates for a considerable time. ${ }^{5}$ In normal lungs there are 50-70 inflammatory cells per alveolus; more than $80 \%$ are alveolar macrophages and less than $1 \%$ neutrophils. ${ }^{6}$ In cigarette smokers the numbers of alveolar macrophages increase by at least $2-4$ times and neutrophils by 10 times. $^{7}$ In vitro studies have shown that alveolar leucocytes and macrophages from cigarette smokers spontaneously release increased amounts of oxidants such as $\mathrm{O}_{2}^{-}$and hydrogen peroxide $\left(\mathrm{H}_{2} \mathrm{O}_{2}\right)$ compared with non-smokers. ${ }^{89}$ It has also been suggested that neutrophils sequestered in the pulmonary circulation are primed to release oxidants in cigarette smokers. ${ }^{10}{ }^{11}$ Passive cigarette smoking has also been associated with increased peripheral blood leucocyte counts which show enhanced release of oxidants. ${ }^{12}$

Oxidants, whether inhaled or generated from leucocytes, can inactivate the major antiprotease in the airways alpha $a_{1}$-proteinase inhibitor $\left(\alpha_{1} \mathrm{PI}\right)$ - by oxidation of its active site. ${ }^{1314}$ This diminishes the binding of $\alpha_{1}$ PI to elastase, hence reducing its inactivation and allowing it to bind to and destroy elastin, leading to emphysema. ${ }^{15}$ Although this hypothesis is supported by in vitro studies, ${ }^{13}$ it has been more difficult to demonstrate convincingly oxidative inactivation of $\alpha_{1}$ PI in vivo. ${ }^{14}$ Other antiproteases which may have a protective role against proteolytic attack and hence may prevent the development of emphysema, such as antileucoprotease, can also be inactivated by oxidants. ${ }^{16}$ Components of the lung matrix - for example, elastin and collagen - can be directly damaged or fragmented by oxidants in cigarette smoke. ${ }^{15}$ Cigarette smoke-derived oxidants also decrease the deformability of circulating neutrophils ${ }^{17}$ leading to increased neutrophil sequestration in the pulmonary microvasculature. ${ }^{10}$ Inhalation of cigarette smoke in hamsters activates neutrophils, increasing their adhesion to the endothelium of both arterioles and venules. ${ }^{18}$ This increased neutrophil adhesion is mediated by superoxide anion in cigarette smoke, since it is inhibited by pretreatment with copper/zinc superoxide dismutase. ${ }^{18}$ Neutrophils sequestered in the pulmonary circulation following cigarette smoke inhalation in the rabbit show increased expression of CD18 integrins, ${ }^{19}$ although this effect has not been demonstrated following in vitro exposure. ${ }^{20}$ Thus, by several mechanisms involving oxidants, cigarette smoke causes neutrophil sequestration in the pulmonary microcirculation ${ }^{10}$ and hence their migration into the airspaces in smokers. These migrated cells remain primed to release more reactive oxygen intermediates. ${ }^{112}$

All tissues are vulnerable to oxidant damage but, by virtue of its location, the airspace epithelium is particularly vulnerable. ${ }^{21}$ Reactive oxygen species may influence airway cells in a number of ways. Oxygen radicals generated close to a cell membrane oxidise membrane phospholipids (lipid peroxidation), a process which may continue in a chain reaction. Lannan and colleagues ${ }^{22}$ showed an oxidantmediated cytotoxicity of human alveolar epithelial cells with decreased epithelial cell adherence and increased detachment and lysis following exposure to cigarette smoke condensate. $\mathrm{Li}$ et $a^{l^{3}}$ demonstrated that the deleterious effects of cigarette smoke condensate on epithelial permeability in vitro in epithelial cell monolayers and in vivo in rat lungs were associated with changes in the homeostasis of the antioxidant glutathione. These in vitro and animal studies are supported by human studies of increased epithelial permeability in smokers, shown by increased technetium-99m labelled diethylenetriamine pentaacetate $\left({ }^{99 m}\right.$ Tc-DTPA) lung clearance. ${ }^{24}$ Preliminary data by Morrison and coworkers showed a further increase in DTPA clearance following acute smoking. ${ }^{25}$

There are technical difficulties in measuring specific markers of oxidative injury. The only definitive way to demonstrate excessive free radical activity is by electron spin resonance which cannot be applied to the study of tissues at present. Instead, investigators rely on indirect measurements of free radical activity in biological fluids such as measurements which assess oxidative damage to lipids, proteins, or DNA. These markers indicate that oxidative damage has occurred, but not that this event is involved in the pathogenesis of the condition.

A major site of free radical attack is on polyunsatured fatty acids in cell membranes, producing lipid peroxidation which generates hydroperoxides and long lived aldehydes. The end products of these reactions are malondialdehyde, ethane, and pentane. Levels of lipid peroxides in plasma and bronchoalveolar lavage fluid, measured as thiobarbituric acid reactive substances (TBARS), are significantly increased in healthy smokers and patients with acute exacerbations of COPD compared with healthy nonsmokers. ${ }^{26-28}$ There is, however, a problem with the specificity of the assays used to measure the metabolites of lipid peroxide reactions.

Evidence for increased oxidative stress in COPD is emerging. Patients with COPD have increased numbers of activated intravascular and airspace neutrophils and macrophages which release more $\mathrm{O}_{2}^{-}$than those from 
healthy controls. ${ }^{29-31}$ Postma and co-workers ${ }^{32}$ showed a correlation between $\mathrm{O}_{2}^{-}$release by peripheral blood neutrophils and bronchial hyperreactivity in patients with COPD. Rahman and colleagues ${ }^{26}$ found increased superoxide anion production from peripheral blood neutrophils obtained from patients with acute exacerbations of COPD. The presence of inflammatory cells capable of inducing an oxidative stress may therefore have a role in the inflammation and airway injury in patients with COPD.

Preliminary data by Rahman and colleagues ${ }^{24}$ used an assay which compared the antioxidant capacity of plasma with the vitamin $\mathrm{E}$ analogue Trolox to measure the Trolox equivalent antioxidant capacity (TEAC). They found that the plasma TEAC was significantly decreased in smokers one hour after smoking and in patients with acute exacerbations of COPD when compared with plasma from age-matched non-smoking controls. Albumin, which has one sulphydryl group per molecule, may form albuminthiol radicals or albumin-SH group conjugates with electrophils present in cigarette smoke. Thus, a profound depletion of plasma protein sulphydryls was shown following cigarette smoke exposure in vitro ${ }^{33}$ which may account for the fall in antioxidant capacity in plasma after smoking. Furthermore, a relationship has been shown between a deficiency in the antioxidant capacity of plasma and the presence of a family history of lung disease. ${ }^{1}$

Many investigators have measured the major plasma antioxidants (ascorbic acid, $\alpha$-tocopherol, uric acid, and sulphydryls) in smokers. ${ }^{3435}$ These studies show a depletion of ascorbic acid, vitamin $\mathrm{E}, \boldsymbol{\beta}$-carotene, and selenium in the serum of chronic smokers. However, circulating red blood cells from cigarette smokers contain increased levels of superoxide dismutase and catalase but similar glutathione peroxidase activity and are more capable of protecting endothelial cells from the effects of hydrogen peroxide than cells from non-smokers. ${ }^{36}$ Galdston and coworkers ${ }^{37}$ found that an indirect measurement of the serum antioxidant activity was decreased in cigarette smokers. They also showed that increased levels of the antioxidant ceruloplasmin occurred in the serum of cigarette smokers. However, these levels did not prevent the inhibition of the antiprotease activity of $\alpha_{1} \mathrm{PI}$ in smokers.

Cross and coworkers ${ }^{33}$ demonstrated that exposure to the gas phase of cigarette smoke in vitro caused loss of plasma protein sulphydryls, bilirubin, and ascorbic acid, whereas uric acid and $\alpha$-tocopherol were not affected. The depletion of plasma antioxidants was associated with increased levels of protein carbonyls and lipid peroxides. ${ }^{37}$ Ascorbate may be a particularly important antioxidant in plasma since whole cigarette smoke induces lipid peroxidation in plasma in vitro which is inhibited by ascorbate. ${ }^{38}$ It has also been shown that protein thiols and ascorbic acid inhibit protein carbonyl formation in plasma following cigarette smoke exposure, whereas bilirubin, uric acid, and $\alpha$-tocopherol do not. ${ }^{33}$ Nitric oxide, which is present in the gas phase of cigarette smoke, reacts with tyrosine to form nitrotyrosine products of proteins in plasma in vitro. ${ }^{39}$ These products can interfere with cell signalling pathways involving tyrosine phosphorylation. Products of nitrotyrosination have been implicated in many lung diseases. ${ }^{40}$

There is limited information on the antioxidant defences of the respiratory tract epithelial lining fluid in smokers and even less for patients with COPD. The important thiol antioxidant glutathione (GSH) is increased in the epithelial lining fluid in the airways of chronic smokers ${ }^{41}$ which is related to humeral markers of inflammation. ${ }^{42}$ The reason for the increase in concentration of GSH in the bronchoalveolar lavage fluid of smokers is not known, but it may be due to cell rupture leading to passive release of
GSH into the extracellular space, specific triggers to cells such as type II pneumocytes or macrophages to increase synthesis and release of GSH, or to plasma exudation as a result of increased alveolar-capillary permeability due to inflammation. Despite the twofold increase in GSH concentrations found in the bronchoalveolar lavage fluid of chronic smokers, GSH may not be present in sufficient quantities to deal with the excessive oxidant burden during acute smoking when acute depletion of GSH may occur. ${ }^{2325}$

Rahman and colleagues ${ }^{43}$ studied the acute effects of cigarette smoke condensate (CSC) on GSH metabolism in a human alveolar epithelial cell line in vitro and in vivo in rat lungs after intratracheal CSC instillation. They found a dose and time-dependent depletion of intracellular soluble GSH, concomitant with the formation of GSH conjugates, without a significant increase in levels of oxidised GSH (GSSG); these results are supported by studies in vivo in animal lungs. ${ }^{40}$ The activities of glutathione synthesis and redox system enzymes such as glutathione peroxidase, gamma-glutamylcysteine synthetase, and glucose-6-phosphate dehydrogenase were transiently decreased in alveolar epithelial cells and in rat lungs after exposure to CSC, possibly as a result of the action of highly electrophilic free radicals on the active site of the enzymes.

Pacht and coworkers ${ }^{44}$ showed reduced levels of vitamin $\mathrm{E}$ in the bronchoalveolar lavage fluid of smokers compared with those in non-smokers. By contrast, alveolar macrophages from smokers have both increased levels of ascorbic acid and augmented uptake of ascorbate. ${ }^{45}$ Similarly, Bui and colleagues ${ }^{46}$ found a marginal increase in vitamin $C$ in the bronchoalveolar lavage fluid of smokers compared with non-smokers. Enhanced activities of the antioxidant enzymes superoxide dismutase and catalase in alveolar macrophages from young smokers has also been demonstrated. ${ }^{47}$ However, Kondo and coworkers ${ }^{48}$ showed that the increased superoxide generation by alveolar macrophages in elderly smokers was associated with decreased antioxidant enzyme activities compared with non-smokers. The activities of copper/zinc superoxide dismutase, glutathione-S-transferase, and glutathione peroxidase are also decreased in alveolar macrophages from elderly smokers. These lower activities were not associated with decreased gene expression but were due to modification at the posttranslational level. ${ }^{48}$

The apparent discrepancies between these studies of different antioxidants in epithelial lining fluid may be due to different smoking histories in chronic smokers, particularly the time relationship to the last cigarette. Activities of superoxide dismutase and glutathione peroxidase are also higher in the lungs of rats exposed to cigarette smoke. ${ }^{49}$ McCusker and Hoidal ${ }^{47}$ demonstrated enhanced alveolar macrophage antioxidant enzyme activities following cigarette smoke exposure which resulted in reduced mortality when the hamsters were subsequently exposed to $>95 \%$ oxygen. They speculated that mammalian alveolar macrophages undergo an adaptive response to chronic oxidant exposure that may ameliorate potential damage to lung cells from oxidant stress. The mechanisms of the induction of antioxidant enzymes in erythrocytes, ${ }^{34}$ alveolar macrophages, ${ }^{47}$ and lungs ${ }^{49}$ by cigarette smoke exposure are not known. However, the induction of anti-oxidant genes is presumed to be involved. We have recently shown in preliminary studies that cigarette smoke increased the expression of gamma-glutamylcysteine synthetase mRNA in human alveolar epithelial cells. ${ }^{50}$

Based on accumulating evidence that oxidants/free radicals play an important part in the pathogenesis of COPD, enhancing the pulmonary antioxidant capacity may therefore be of potential therapeutic benefit in this condition. This can be achieved in two ways - either by enhancing 
endogenous antioxidant enzymes to limit the generation of free radicals or by increasing non-enzymatic antioxidants which can detoxify reactive oxygen species once they are formed. A further possible intervention is to reduce the recruitment or the activation of inflammatory cells in the lungs, so limiting the production of reactive oxygen intermediates. However, it would be premature to recommend antioxidant therapy in COPD before we have a greater knowledge of the nature of free radicals/oxidants involved and their mechanisms in the pathogenesis of COPD. Additionally, it is important to determine the mechanism of antioxidant depletion and, in particular, to establish which antioxidants are depleted in biological fluids in patients with acute COPD to enable a logical strategy for antioxidant therapy to be developed.

Supported by the Norman Salvesen Emphysema Research Trust and the British Lung Foundation.

Correspondence to: Dr W MacNee.

Unit of Respiratory Medicine,

I RAHMAN

Department of Medicine,

W MacNEE

Royal Infirmary,

Edinburgh EH3 9YW,

$U K$

1 Taylor JC, Madison R, Kosinska D. Is antioxidant deficiency related to chronic obstructive disease? Am Rev Respir Dis 1986;134:285-9.

2 Pryor WA, Stone K. Oxidants in cigarette smoke: radicals, hydrogen peroxides, peroxynitrate, and peroxynitrite. Ann N Y Acad Sci 1993;686: $12-28$.

3 Sies H. Oxidative stress: oxidants and antioxidants. London: Academic Press, 1991: xv-xxii.

4 Church T, Pryor WA. Free-radical chemistry of cigarette smoke and its toxicological implications. Environ Health Perspect 1985;64:111-26.

5 Nakayama T, Church DF, Pryor WA. Quantitative analysis of the hydrogen peroxide formed in aqueous cigarette tar extracts. Free Rad Biol Med 1989; 7:9-15.

6 Saltini C, Hance A, Ferrans V, Baset F, Bitterman P, Crystal RG. Accurate quantitation of cells recovered by bronchoalveolar lavage. Am Rev Respir Dis 1984;130:650-8.

7 Hunninghake GW, Crystal RG. Cigarette smoking and lung destruction: accumulation of neutrophils in the lungs of cigarette smokers. Am Rev Respir Dis 1983;128:833-8.

8 Schaberg T, Haller H, Rau M, Kaiser D, Fassbender M, Lode H. Superoxide anion release induced by platelet-activating factor is increased in human alveolar macrophages from smokers. Eur Respir $\mathcal{f}$ 1992;5:387-93.

9 Ludwig PW, Hoidal JR. Alterations in leukocyte oxidative metabolism in cigarette smokers. Am Rev Respir Dis 1982;126:977-80.

10 MacNee W, Wiggs B, Berzberg AS, Hogg JC. The effects of cigarette smoking on neutrophil kinetics in human lungs. N Engl f Med 1989;321: 924-8.

11 Brown D, Drost E, Donaldson K, MacNee W. Deformability and CD11/ CD18 expression of sequestered neutrophils in normal and inflamed lungs. Am $\mathcal{F}$ Respir Cell Mol Biol 1995;13:531-9.

12 Anderson R, Theron AJ, Richards GA, Myers MS, Rensburg AJV. Passive smoking by human sensitizes circulating neutrophils. Am Rev Respir Dis 1991;144:570-4.

13 Hubbard RC, Ogushi F, Fels GA, Cantin AM, Courtney M, Crystal RG. Oxidants spontaneously released by alveolar macrophages of cigarette smokers can inactivate the active site of alpha 1-antitrypsin, rendering it ineffective as an inhibitor of neutrophil elastase. $\mathcal{F}$ Clin Invest 1987;80: 1289-95.

14 Carp H, Miller F, Hoidal JR, Janoff A. Potential mechanisms of emphysema: alpha 1-proteinase inhibitor recovered from lungs of cigarette smokers contains oxidised methionine and has decreased elastase inhibitory capability. Proc Natl Acad Sci USA 1982;79:2041-5.

15 Cantin A, Crystal RG. Oxidants, antioxidants and the pathogenesis of emphysema. Eur $\mathcal{F}$ Respir Dis 1985;66(Suppl 139):7-17.

16 Cramps JA, van Twisk C, Dijkman JH. Oxidative inactivation of antileukoprotease by triggered polymorphonuclear leucocytes. Clin Sci 1988; 75:53-62.

17 Drost EM, Selby C, Bridgeman MME, MacNee W. Decreased leukocyte deformability after acute cigarette smoking in humans. Am Rev Respir Dis 1993;148:1277-83.

18 Lehr HA, Kress E, Menger MD, Friedl HP, Hubner C, Arfors KE, Messmer $\mathrm{K}$. Cigarette smoke elicits leukocyte adhesion to endothelium in hamsters: inhibition by CuZnSOD. Free Rad Biol Med 1993;14:573-81.

19 Klut ME, Doerschuk CM, Hogg JC, Vaneedon SF, Burns AR. Activation of neutrophils within pulmonary microvessels of rabbits exposed to cigarette smoke. Am $¥$ Respir Cell Mol Biol 1993;9:82-90.
20 Selby C, Drost E, Brown D, Howie S, MacNee W. Inhibition of neutrophil adherence and movement by acute cigarette smoke exposure. Exp Lung Res 1992;18:813-27.

21 Cross CE, Vab der Vliet A, O'Neill CA, Louie S, Halliwell B. Oxidants, antioxidants, and respiratory tract lining fluids. Envirn Health Perspect 1994;102(Suppl 10):185-91.

22 Lannan S, Donaldson K, Brown D, MacNee W. Effects of cigarette smoke and its condensates on alveolar cell injury in vitro. Am $\mathcal{F}$ Physiol 1994;
266:L92-100.

$23 \mathrm{Li}$ XY, Donaldson K, Rahman I, MacNee W. An investigation of the role of glutathione in the increased epithelial permeability induced by cigarette smoke in vivo and in vitro. Am $\mathcal{F}$ Respir Crit Care Med 1994;149:1518-25. 24 Jones JG, Lawler P, Crawley JCW, Minty BD, Hulands G, Veall N. Increased alveolar epithelial permeability in cigarette smokers. Lancet 1980;i:66-68.

25 Morrison D, Lannan S, Langridge A, Rahman I, MacNee W. Effect of acute cigarette smoking on epithelial permeability, inflammation and oxidant status in the airspaces of chronic smokers. Thorax 1994;49:1077.

26 Rahman I, Morrison D, Wehbe L, Ramsay C, Donaldson K, MacNee W. Oxidant/antioxidant imbalance in smokers and in patients with chronic obstructive pulmonary disease. Am $\mathcal{F}$ Respir Crit Care Med 1996 (in press)

27 Petruzzelli S, Hietanen E, Bartsch H, Camus AM, Mussi A, Angeletti CA et al. Pulmonary lipid peroxidation in cigarette smokers and lung patients.

28 Bridges AB, Scott NA, Parry GJ, Belch JJF. Age, sex, cigarette smoking and indices of free radical activity in healthy humans. Eur $\mathcal{F}$ Med 1993; $2-8$.

29 Selby C, Drost E, Lannan S, Wraith PK, MacNee W. Neutrophil retention in the lungs of patients with chronic obstructive pulmonary diseases. $\mathrm{Am}$ Rev Respir Dis 1991;143:1359-64.

30 Linden M, Ramussen JB, Pitulainen E, Tunek A, Larson M, Tegner H, et al. Airway inflammation in smokers and nonobstructive and obstructive chronic bronchitis. Am Rev Respir Dis 1993;148:1226-32.

31 Renkema TEJ, Postma DS, Noordhoek JA, Shriter HJ, Kauffman HF. Influence of in vivo prednisolone on increased in vitro superoxide anion generation by neutrophils in emphysema. Eur Respir f 1993;6:90-5.

32 Postma DS, Renkema TEJ, Noordhoek JA, Faber H, Sluiter HJ, Kauffman H. et al. Association between nonspecific bronchial hyperreactivity and superoxide anion production by polymorphonuclear leukocytes in chronic airflow obstruction. Am Rev Respir Dis 1988;137:57-61.

33 Cross CE, O’Neill CA, Reznick AZ, Hu ML, Marcocci L, Packer L, Frei B. Cigarette smoke oxidation U, et al. Cigarette smoke-mediated oxidant stress, phagocytes, vitamin C, vitamin E and tissue injury. Ann NY Acad Sci USA 1993;686:53-65.

35 Chow CK, Thacker R, Bridges RB, Rehm SR, Humble J, Turbek J. Lower levels of vitamin $\mathrm{C}$ and carotenes in plasma of cigarette smokers. $\mathcal{f} \mathrm{Am}$ levels of vitamin $C$ and car $1986 ; 5: 305-12$.

36 Toth KM, Berger EM, Buhler CJ, Repine JE. Erythrocytes from cigarette smokers contain more glutathione and catalase and protect endothelial cells from hydrogen peroxide better than do erythrocytes from nonsmokers. Am Rev Respir Dis 1986;134:281-4.

37 Galdston M, Levytska V, Schwartz MS, Magnusson B. Ceruloplasmin increased serum concentration and impaired antioxidant activity in cigarette smokers, and ability to prevent suppression of elastase inhibitor capacity of alpha-1-proteinase inhibitor. Am Rev Respir Dis 1984;129: 258-63.

38 Frei B, Forte TM, Ames BN, Cross CE. Gas phase oxidants of cigarette smoke induce lipid peroxidation and changes in lipoprotein properties in human blood plasma. Biochem $\mathcal{F}$ 1991;277:133-8.

39 Eiserich JP, Vossen V, O'Neill CA, Halliwell B, Cross CE, Van der Vliet A. Molecular mechanisms of damage by excess nitrogen oxides: nitration of tyrosine by gas-phase cigarette smoke. FEBS Lett 1994;353:53-6.

40 Haddad IY, Pataki G, Hu P, Galliani C, Beckman JS, Matalon S. Quantitation of nitrotyrosine levels in lung sections of patients and animals with tation of nitrotyrosine levels in lung sections of patier

41 Cantin AM, North SL, Hubbard RC, Crystal RG. Normal alveolar epithelial lung fluid contains high levels of glutathione. $\mathcal{F}$ Appl Physiol 1987;63: 153-7.

42 Linden M, Hakansson L, Ohlsson K, Sjodin K, Tegner H, Tunek A, et al. Glutathione in bronchoalveolar lavage fluid from smokers is related to humoral markers of inflammatory cell activity. Inflammation 1989;13: 651-8.

43 Rahman I, Li XY, Donaldson K, Harrison DJ, MacNee W. Glutathione homeostasis in alveolar epithelial cells in vitro and lung in vivo under oxidative stress. Am f Physiol: Lung Cell Mol Biol 1995;13:L285-92.

44 Pacht ER, Kaseki H, Mohammed JR, Cornwell DG, Davis WR. Deficiency of vitamin $\mathrm{E}$ in the alveolar fluid of cigarette smokers. Influence on alveolar macrophage cytotoxicity. $\mathcal{F}$ Clin Invest 1988;77:789-96.

45 McGowan SE, Parenti CM, Hoidal JR, Niewoehner DW. Differences in ascorbic acid content and accumulation by alveolar macrophages from cigarette smokers and non-smokers. $\mathcal{F}$ Lab Clin Med 1984;104:127-34.

46 Bui MH, Sauty A, Collet F, Leuenberger P. Dietary vitamin C intake and concentrations in the body fluids and cells of male smokers and nonsmokers. F Nutr 1992;122:312-36.

$47 \mathrm{McCusker} \mathrm{K}$, Hoidal J. Selective increase of antioxidant enzyme activity in the alveolar macrophages from cigarette smokers and smoke-exposed hamsters. Am Rev Respir Dis 1990;141:678-82.

48 Kondo T, Tagami S, Yohioka A, Nishumura M, Kawakami Y. Current smoking of elderly men reduces antioxidants in alveolar macrophages. Am $₹$ Respir Crit Care Med 1994;149:178-82.

49 York GK, Pierce TH, Schwartz LS, Cross CE. Stimulation by cigarette smoke of glutathione peroxidase system enzyme activities in rat lung. Arch Environ Health 1976;31:286-90.

50 Rahman I, Lawson M, Harrison DJ, MacNee W. $\gamma$-glutamylcysteine synthetase induction by cigarette smoke exposure in alveolar epithelial cells. Respir Med 1994;88:809.
thetase induction by cigat 